\title{
Narrativas de vida como estratégia de ensino-aprendizagem na formação em saúde
}

Jaquelina Maria Imbrizi(a)

Fernando Sfair Kinker ${ }^{(b)}$

Adriana Barin de Azevedo(c) Andrea Perosa Saigh Jurdi(d)

\section{Introdução}

No âmbito acadêmico, a discussão sobre as novas tendências de ensino vem ganhando espaço na agenda da formação docente. As Diretrizes Curriculares Nacionais $(D C N)^{1}$ preconizam que a formação do profissional de saúde deve ser condizente com os princípios e diretrizes do Sistema Único de Saúde². Nesse contexto, cursos e universidades precisam rever posições pedagógicas e currículos de formação. Ao propor que os cursos de graduação tenham como eixo norteador a integralidade, novas concepções de saúde e assistência passam a fazer parte dos currículos.

Temos o desafio de pensar e construir a formação de um profissional apto para o trabalho em equipe de maneira interdisciplinar, compreendendo a experiência singular do adoecimento - e não só a doença -, analisando a complexidade do contexto social de modo a trabalhar mais próximo das culturas populares, constituindo redes cuidadoras entre os serviços de saúde e estabelecendo relações orgânicas entre estruturas de serviço e matrizes de ensino/formação. Nesse cenário, docente e discente assumem novos papéis e, como se trata de uma relação complementar, caberia ao professor cultivar a escuta e postura flexível frente aos modos de fala e participação de seus estudantes que, por sua vez, precisam assumir um papel cada vez mais ativo em busca de seu conhecimento e exercitar sua criatividade e curiosidade científica ${ }^{3}$.

Em consonância com a proposta inovadora do projeto político-pedagógico do campus Baixada Santista da Unifesp, que prevê uma formação interprofissional com ênfase em metodologias ativas, as narrativas são estratégias de ensinoaprendizagem utilizadas em alguns módulos curriculares dos cursos de graduação, a partir da proposta pedagógica desenvolvida no eixo comum Trabalho em Saúde.

Esse eixo, comum a todos os cursos de graduação, utiliza a narrativa no segundo ano da formação, com o intuito de aproximar os estudantes de um trabalho com sujeitos e suas necessidades complexas, conhecendo assim a história de vida daquele que demanda cuidado e privilegiando a experiência da escuta e da implicação no trabalho em saúde.

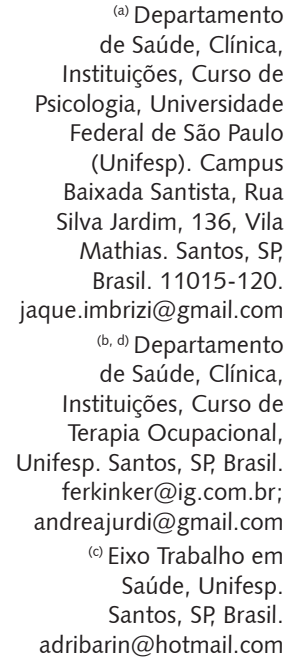

(a) Departamento de Saúde, Clínica, Instituições, Curso de Psicologia, Universidade Federal de São Paulo (Unifesp). Campus Baixada Santista, Rua Silva Jardim, 136, Vila Mathias. Santos, SP Brasil. 11015-120. jaque.imbrizi@gmail.com (b, d) Departamento de Saúde, Clínica, Instituições, Curso de Terapia Ocupacional, Unifesp. Santos, SP, Brasil. ferkinker@ig.com.br; andreajurdi@gmail.com

(c) Eixo Trabalho em Saúde, Unifesp. Santos, SP, Brasil. adribarin@hotmail.com 
Neste texto, serão apresentadas três diferentes experiências de professores que utilizam o processo de produção escrita da narrativa como método de avaliação, que substitui a clássica prova. No curso de Psicologia, no módulo "Psicologia, Ideologia e Cultura", no segundo ano de formação, a principal atividade de avaliação solicitada é a entrega de um memorial, cujo objetivo é a produção escrita da trajetória de vida com vistas à articulação entre as experiências do estudante e os textos e conceitos trabalhados no módulo. No curso de Terapia Ocupacional, no módulo "Atividades Lúdicas e Lazer", é solicitado ao estudante de terceiro ano do curso de graduação que escreva sua biografia, tendo como foco o brincar na sua infância. No eixo comum "Trabalho em Saúde", no segundo ano de formação, no módulo "Prática Clínica Integrada: análise de demandas e necessidades de saúde", estudantes têm o desafio de escrever a narrativa de história de vida dos usuários de um Núcleo de Apoio Psicossocial (Naps). Nesse caso, eles são convidados a cartografar as relações entre a trajetória de vida de usuários da Saúde Mental e as redes de cuidado e apoio ofertadas para essas pessoas em situação de vulnerabilidade social.

Portanto, esse texto se propõe tanto a discutir a produção de narrativas como uma importante estratégia de ensino-aprendizagem na formação profissional quanto apresentar a experiência desses professores na leitura e avaliação dessas produções escritas. Para isso, dividimos o texto em três tópicos: a discussão teórica a respeito da narrativa, as três experiências e a análise de seus impactos sobre a formação dos estudantes e docentes.

\section{Discussão teórica sobre narrativas}

A proposta de produção escrita de narrativas de vida na graduação em saúde parte do princípio apontado por Adorno ${ }^{4}$ de que: "[...] a educação tem sentido unicamente como educação dirigida a uma autorreflexão crítica" (p. 121). Ou seja, os professores são convidados a compreender a formação cultural como um processo singular que pode dar oportunidade à reflexão sobre a história da cultura na qual o estudante e o docente estão inseridos, pois tanto a produção simbólica quanto as condições materiais de existência de uma sociedade, mais do que um pano de fundo, precisam ser discutidas como produtoras de subjetividade.

Nesse sentido, no que se refere à singularidade da matéria que compõe as narrativas, o estudante, ao escrever sobre as trajetórias de vida, está rememorando o passado, o seu e do outro, e se aproximando das técnicas de si e dos modos como gregos e romanos investiram na produção de subjetividade ${ }^{5}$. Essas técnicas incluíam a meditação, a dieta, os exercícios físicos e espirituais, a coragem de dizer a verdade, também denominada parrésia, e a escrita de si. Essa última está associada ao cuidado de si, mas também à abertura ao outro, como atividade sobre o próprio Eu em um contexto de relações e laços sociais.

Foucault ${ }^{6}$ cita duas formas de escrita de si: hypomnemata e correspondência. Os primeiros eram cadernos de notas que, em si mesmos, constituíam anotações sobre a fala de alguém e um texto lido. Já nas diversas formas de correspondência endereçadas ao outro, na maioria das vezes, os assuntos versavam sobre modos de compartilhar notícias sobre questões de saúde e atividades cotidianas. O filósofo insiste que, ao escrever para outro, o sujeito é surpreendido com ideias desconhecidas até para si mesmo: "Escrever é, pois, 'mostrar-se', dar-se a ver, fazer aparecer o rosto próprio junto ao outro"6 (p. 150).

Vernant ${ }^{7}$ afirma que, na Grécia Antiga, que é o contexto histórico estudado por Foucault, não existiam confissões e diários íntimos e, ao contrário da busca pela intimidade do Eu, o importante era situar o sujeito no mundo. Nas palavras do autor: "A introspecção não existe. [...] O sujeito é extrovertido. Do mesmo modo como o olho não se vê a si próprio, o indivíduo para se apreender olha para outro lado, para o exterior" (p. 38)

Tania Rivera ${ }^{8}$ afirma que as produções artísticas têm a chance de explorar e atualizar isso que constitui o sujeito fora de si - no outro. A autora analisa a produção escrita do artista plástico Hélio Oiticicca, que se apropria de elementos diversos para produzir seu texto: "Apropriação: tornar próprio o que é do outro, para passá-lo adiante e tornar-se outro, nessa passagem. A arte é, nesse 
sentido, marcada pela transitoriedade [...] na medida em que ela não é mais do que um transito entre sujeitos". (p. 58)

A questão da transitoriedade da arte é contemplada em dois textos de Sigmund Freud. No primeiro texto, Freud ${ }^{9}$ insere a questão de apreciar a beleza e os bens culturais, apesar de sua transitoriedade na vida, engolida pela voracidade do tempo no capitalismo. Já no segundo texto ${ }^{10}$, o psicanalista aproxima o processo criativo do escritor ao brincar no período da infância, incluindo seus jogos. Pois, o lúdico e a escrita criativa pressupõem a capacidade do sujeito de devanear, ausentar-se momentaneamente do mundo externo e produzir torções que criem e transformem a realidade e a experiência com o tempo. É no processo de socialização nas sociedades ocidentais que o sujeito considerado adulto precisa esquecer as brincadeiras e se centrar no tempo cronológico e útil. A maestria de um escritor criativo estaria na possibilidade de produzir simbolicamente um material que desperte o desejo criativo e brincante na pessoa que lê o texto literário.

Imbrizi et al. ${ }^{11,12}$ recorrem ao livro "Istambul: memória e cidade"13 para afirmarem que a produção de narrativa de história de vida está mais próxima da arte, no caso a literatura, do que dos ditames da ciência positivista. O literato convida os leitores a refletirem sobre como o seu Eu está ceifado pela topografia de sua cidade natal; ele escreve sobre si e sua família e ao mesmo tempo delineia as peculiaridades da cultura de Istambul e, assim, propõe um movimento extemporâneo no qual ocupa a posição de um narrador que transita entre o lugar da criança, do adolescente e do adulto. É o tempo do inconsciente e das experiências do escritor, no qual espaço e tempo se misturam na escrita de suas reminiscências e possibilitam a reflexão acerca do peso da memória coletiva que embaralha fato e ficção.

Os autores aqui elencados nos apoiam na problematização da narrativa como ferramenta que possibilita o processo criativo na elaboração de um material escrito, a transitoriedade entre a verticalidade da história singular e a horizontalidade da cultura, e a reflexão acerca da constituição subjetiva no encontro com a diferença. Assim, o uso da ferramenta narrativa pode recuperar o lugar que a criação ética e estética tem na produção do conhecimento e na formação profissional.

A partir deles, foi possível criar alguns critérios para que os professores considerassem no material escrito dos estudantes: 1) cartografar a subjetividade é um processo e, portanto, sempre inacabado; 2) afirmar a singularidade em suas articulações com o contexto social: as redes de cuidado, as atividades lúdicas, artísticas e coletivas; e 3) confirmar um exercício ético: a luta para evidenciar a inventividade da vida.

Tendo esses critérios como referência é que apresentaremos as três experiências de formação.

\section{A narrativa de história de vida e a formação em Psicologia}

O convite para a reflexão sobre seu processo de formação tem sido uma atividade sugerida aos estudantes matriculados no módulo "Psicologia, ideologia e cultura". Eles são convidados a produzir um memorial e o que nos interessa nessa proposição é inserir a experiência de vida como objeto privilegiado na produção de conhecimento.

No caso específico de nossa experiência no módulo e à luz das ideias de Foucault ${ }^{6}$, podemos dizer que o memorial comporta um momento no qual o estudante coloca em exercício as anotações que faz de suas leituras e daquilo que foi dito em sala de aula, com o intuito de produzir reflexões sobre sua própria existência.

O memorial é um convite para que o estudante descreva suas experiências de vida e localize os valores culturais que são construídos historicamente e transmitidos por meio de pessoas, coisas, arquiteturas, ambiências e da topografia da cidade na qual está inserido.

No que se refere aos desafios da escrita, a estudante A escreveu: "Inicio esse texto com o sentimento de alguém que escreve sem saber muito bem para quem e para quê. De certa forma, escrevo a mim mesma, numa tentativa esperançosa de me encontrar nessa teia de relações e criações chamada cultura". (Estudante A)

Aqui, a escrita de si como algo interminável está presente e se abre para reinvenções. O embate com o vazio da folha em branco está transcrito no texto, o Eu e o outro parecem perdidos, mas há a possibilidade de transito entre eles. 
O estudante B fez uso da música como tema para o desenvolvimento de seu memorial e articula-a com as discussões do texto de Adorno e Horkheimer ${ }^{14}$ sobre a indústria cultural, que é vista: "[...] como delimitadora da verossimilhança no campo das artes, fazendo uso de recursos como a repetição para solidificar sentidos favoráveis ao mercado capitalista. [...] minha percepção sonora pode estar determinada pelos meios de produção e pelas relações de poder" (Estudante B)

Nesse trecho, há o exercício da autorreflexão sobre sua própria cultura como aquela que molda a audição das pessoas.

Os trechos extraídos do capítulo do livro de Marcuse ${ }^{15}$ pela estudante $C$ são contundentes e não poupam críticas à instituição universitária, que transmite e impõe sutilmente suas ideologias. Para essa estudante, a afirmação do filósofo de que a independência de pensamento está perdendo sua função crítica é inspiração para um dos trechos de seu memorial: "Os discursos de liberdade de escolha e pensamento são frequentes, mas é em atitudes simples, como cortar a fala de um colega que se expressa [...] que percebemos que '[...] sob o jugo de um todo depressivo, a liberdade pode ser transformada em instrumento de dominação'15 (p. 28)". O que chama nossa atenção nesse trecho é o fato de que o memorial abre oportunidade para reflexões sobre as anotações de ideias dos autores que serão, posteriormente, incorporadas na escrita.

Os memoriais produzidos pelos estudantes da turma do segundo semestre de 2014 foram surpreendentes no que diz respeito à escolha de temas para o desenvolvimento das narrativas de história de vida: a) a escrita direcionada ao outro; b) a música; c) o espaço universitário; d) a relação com a irmã gêmea reveladora no seguinte trecho: "Sempre tivemos o mesmo corte de cabelo, sempre estudamos na mesma sala de aula, e tudo isso não porque éramos iguais, mas porque tínhamos medo de ser diferentes" (Estudante $M$ ); e muitos outros que não cabe enumerar aqui.

É possível perceber que o tema escolhido para desenrolar a escrita traz à tona a singularidade de cada estudante. Esse exercício é um fator importante a constar como elemento na formação dos profissionais de saúde para que estes estejam mais abertos para aquilo que singulariza os sujeitos inseridos em uma cultura comum e compartilhada.

\section{A narrativa como recurso para a formação lúdica do estudante de terapia ocupacional}

As atividades humanas são instrumento privilegiado das ações dos profissionais e constituem o elemento centralizador do processo terapêutico ocupacional ${ }^{16}$. Compreende-se que privilegiá-las para a compreensão do indivíduo no mundo requer trazer à tona a experiência, o fazer e o estar no mundo com o outro. Portanto, nos ocupamos de lançar luz sobre a experiência de si no mundo e sobre a experiência de estar e fazer com o outro.

O módulo "Atividades Lúdicas e Lazer" tem por objetivo que o estudante compreenda a importância das atividades lúdicas e de lazer ao longo do desenvolvimento humano e o brincar como legítimo depositário da cultura de transmissão oral de crianças, jovens, adultos e idosos.

O brincar constitui-se em um sistema que integra a vida social dos indivíduos e faz parte do patrimônio lúdico-cultural, traduzindo valores, costumes, formas de pensamento e ensinamentos, estabelecendo outros jeitos de viver e de fazer, criando novos padrões de sociabilidade permeados pela amizade, pela cooperação e pela noção de responsabilidade coletiva. Nesse processo, utiliza-se a produção de inventários e a ludobiografia, formas de narrativas distintas que possibilitam ao estudante experimentar a atividade, elaborá-la, construí-la individualmente e coletivizá-la posteriormente. Nesse caso, falamos de narrativas da experiência que trazem consigo o potencial de revisitar a memória lúdica e de constituí-la no presente. Narrar novamente a experiência partilhada, refletir sobre as estratégias para produzir lembranças e comunicá-las, constituindo memórias e compreensões sobre o tempo, é uma forma de ressignificar o passado no presente e apresentá-lo em sua novidade.

Inventário deriva do latim inventarium, que significa relação de bens deixados por alguém e documento ou lista em que se encontram registrados bens contendo ou não uma enumeração detalhada ou minuciosa dos mesmos. Partindo dessa premissa, é solicitado aos estudantes que realizem uma pesquisa de suas brincadeiras e brinquedos, de seus pais e de seus avós, permitindo a cada um 
a sistematização do material de acordo com seu estilo e criatividade. A produção do inventário lúdico acontece ao longo do módulo e é utilizada como produto final para avaliação. É importante salientar que, nesse processo de pesquisar sobre o brincar intergeracional, os estudantes entram em contato com manifestações diversas de narrativas familiares que, até então, eram ignoradas por eles. Não é incomum que avós, pais e tios relatem situações difíceis na infância nas quais não permitiam que brincassem. Essas narrativas mostram o lúdico que emerge de condições adversas de vida: em algum momento foi possível brincar, construir um brinquedo, como um alívio para superar dias difíceis.

Em paralelo, os estudantes constroem sua própria ludobiografia, na qual desvelam a ludicidade presente em sua história de vida e despertam o ser brincante que cada um traz consigo. Utiliza-se o filme "Tarja branca - a revolução que faltava" ${ }^{17}$ como disparador, partindo de um conselho:

[...] hoje, amanhã, ou por esses dias, não se acanhe de selecionar uma foto de que você mais goste de quando era criança [...]. Preferencialmente uma foto que vai rememorar aquela criança viva, ativa, sorridente, brincalhona, lúdica que você foi. Olhe para ela e faça as seguintes perguntas: como ela está e por onde ela está? [...]. A possibilidade de nos assustarmos é altíssima. E de repensarmos algumas coisas também.

A partir desse conselho, vemos que essa tarefa não é tão simples, principalmente quando nos debruçamos sobre uma caixa velha e infelizmente percebemos que nos tornamos sérios demais e ocupados demais para brincar, não somente com os outros, mas com nós mesmos ${ }^{10}$. Fomos acostumados a acreditar que a seriedade é sinônimo de competência e que a brincadeira é sinônimo de imperfeição, ou seja, que é imprudente e desnecessária na maturidade adulta. A estudante D escreve sobre a desqualificação do brincar: "Até chegar um determinado momento da minha vida em que brincar de qualquer maneira já não parecia certo, eu tinha obrigações, tinha gente que precisava de mim e assumi responsabilidades que não eram minhas. A vida me cobrava ser séria e eu o fiz, desisti completamente de brincar" (Estudante D).

A narrativa da estudante $\mathrm{E}$ fala da dificuldade de entrar em contato com a memória lúdica: "Confesso nunca ter parado para pensar no meu brincar e que foi muito difícil conseguir me lembrar das brincadeiras e do que eu realmente gostava de fazer".

Quando tomamos a narrativa como forma de rever a escrita do passado à luz do presente e revisitar o nosso ser brincante, instaura-se um trabalho de certa forma artesanal por parte do narrador, que, diante de sua experiência, constrói uma forma particular de concebê-la, envolvendo-a de sentimentos e sentidos próprios. A narrativa de $\mathrm{F}$ reaviva experiências brincantes: "O brincar me moldou, me tornou o que sou hoje e, como disse, acredito que essa brincadeira não tem fim. Ela vai se modificando com o passar do tempo. Nossa risada tem outros motivos, nossa diversão muda" (Estudante F).

Deixar registrada essa vivência por meio de imagens e escrita tem como objetivo não só contribuir para a reflexão sobre diferentes metodologias que podem ser utilizadas pelo docente para sensibilizar o estudante na construção do ser terapeuta, mas também divulgar a poética e a criatividade presentes em experimentações realizadas no módulo.

Para Fortuna ${ }^{18}$, talvez seja na ludicidade que possamos pensar em uma nova formação para nossos estudantes, uma vez que esta não desaparece ao término da infância. Ela não só persiste na vida adulta como se metamorfoseia nos modos de ser, de pensar, de aprender e ensinar, nos modos de viver.

\section{A produção de narrativas e a experiência de formação junto a um Núcleo de Atenção Psicossocial}

O módulo "Prática Clínica Integrada: análise de demandas e necessidades de saúde" é oferecido a estudantes do segundo ano dos seis cursos de graduação (Psicologia, Terapia Ocupacional, Fisioterapia, Serviço Social, Educação Física e Nutrição) em turmas mistas. Com o objetivo de desenvolver a capacidade dos estudantes de criar vínculo e aguçar a escuta, propõe-se uma atenção às diversas 
dimensões do processo saúde/doença/cuidado por meio do encontro com usuários de um dos Naps de Santos, para ouvir suas histórias de vida e produzir uma narrativa a partir delas.

Durante um semestre, duplas de estudantes de cursos diferentes realizam visitas quinzenais aos usuários desse serviço, que ocorrem ou no NAPS ou nas suas residências, de acordo com a preferência deles, com o intuito de conhecer suas histórias. As histórias contam um percurso pelas redes de cuidado e apoio ofertadas a essas pessoas em situação de vulnerabilidade social e também as errâncias vividas por elas no contato com sujeitos e com situações diversas. Muitas vezes, o ato de ouvir as palavras do outro remete o estudante a sua própria história e a acontecimentos que nem cabem em palavras. Por isso, a tarefa de escrever uma narrativa aparece como um grande desafio para um estudante que já inicia sua formação aproximando-se da história de vida de outra pessoa que mobiliza nele muitas questões.

Para dar conta da multiplicidade de questões que surgem em cada visita, realizamos uma conversa coletiva supervisionada por nós docentes, que se intercala aos encontros com os usuários, com o intuito de partilhar a experiência e criar um espaço de apoio às dificuldades dos estudantes. O que se observa cada vez que o estudante conta sobre sua experiência é que tanto as memórias esquecidas dos usuários quanto as suas próprias são reativadas a partir desse encontro. Os estudantes relatam situações inusitadas, sem protocolos, nem roteiros predefinidos, mas com uma direção geral e uma disposição estratégica de abertura para o novo, que caracteriza os processos cartográficos ${ }^{19}$. É o que percebemos a partir do que a estudante $\mathrm{G}$ escreve em seu diário de campo, instrumento de apoio que serve de base para a posterior produção da narrativa: "Estou me impressionando muito com esse trabalho e com minhas reações em relação a isso. Minha ansiedade a cada semana é maior, e na verdade não queria que fossem tão poucos encontros assim" (Estudante G).

Uma das questões dos estudantes é em relação à expectativa em ouvir uma história contada de modo linear e cronológico. Eles entram em contato com uma memória dispersiva, um discurso fragmentado produzido a partir de um pensamento desconexo. O que se escuta são dados confusos, por vezes contraditórios, como no caso de um usuário que em um dia diz ter três filhos e no outro diz não ter nenhum. Trata-se de um modo de narrar e se ver com a própria história, que é sempre singular.

É deste modo que o processo formativo desloca o foco no conhecimento da doença e dos sintomas, apostando na abertura e disponibilidade à aventura inesperada do encontro, com suas vicissitudes. É essa abertura que os permite afetar-se e produzir um novo olhar e entendimento sobre a experiência dos usuários. De fato, estes deixam de ser doentes mentais para serem sujeitos com histórias ricas, vertiginosas, emocionantes e, quase sempre, sofridas. Há, portanto, uma aproximação com a experiência do sofrimento que tanto pode dar a sensação de dilacerar, desmanchar, quanto a de se metamorfosear radicalmente. Como diz a estudante $\mathrm{H}$ : "Observando essa história fico pensativa, tentando me colocar no lugar desse casal que passa por tantas dificuldades... Com os encontros chegando ao fim, me pego pensando em como será essa despedida, não sei ao certo como colocar um ponto final nesse tipo de relação que nunca tive antes" (Estudante $\mathrm{H}$ ).

Não é tarefa simples aprender a acolher a experiência do usuário, decifrar seu discurso caleidoscópico e criar pela escrita um trabalho de cuidado. No entanto, o que se percebe é que este cuidado se efetua quando o estudante, futuro profissional, é capaz de ouvir, antes de tentar encaixar o sintoma, a doença, em um saber preexistente. Antes de chamar de delírio um modo de dizer a realidade, pode-se escutar naquelas falas um modo singular de gaguejar na própria língua, como diz Deleuze $^{20}$ a respeito dos escritores, que são capazes de dizer algo vital que a linguagem corrente, com sua sintaxe, é incapaz de dizer. Podemos afirmar que esse discurso caleidoscópico não se aprisiona nos fascismos da linguagem e produz fendas em um pensamento hegemônico, ousando dizer o inaudito.

Pela escrita, que é matéria de mistura entre narrador-escritor e personagem-usuário, é possível dar voz a estes pensamentos não legitimados e compor uma história. Ouvir o que os usuários têm a dizer neste encontro que ocorre fora da universidade, em seu próprio território, permite perceber outras coisas. O contato com a realidade dos usuários - marcada por condições precárias de vida, já que muitos deles habitam pequenos quartos de cortiços do centro da cidade, onde predomina a falta de luminosidade, a umidade, o mofo - acessa de modo afetivo uma história de vida. 
A escrita surge deste contexto, onde o lugar do saber é colocado em análise, onde os estigmas referentes à saúde mental perdem sentido diante da experiência e onde uma vida é narrada em seus gestos, não cabendo mais na descrição de um diagnóstico ou de uma doença. É o que aparece nesta narrativa: "F. é uma senhora de 64 anos, divorciada, que atualmente mora com sua mãe e netas. [...] Essa mulher guerreira, que luta por sua família a cada dia, é uma pessoa admirável, que se mostrou muito honesta, justa, simpática, aberta para ajudar quem for necessário e, sobretudo, forte" (Estudante J).

Por isso, quando nos perguntamos como essa experiência pode contribuir para uma formação profissional de áreas que lidam com as expectativas e as necessidades dos sujeitos, podemos dizer que se trata antes de tudo de uma abertura para o encontro, da capacidade de escutar e aprender a cartografar a própria subjetividade e a do outro.

\section{Considerações finais}

Em 23 anos eu nunca parei para pensar na minha vida [...] numa perspectiva crítica e analítica. [...] É como se eu estivesse deixando de "vir apenas vivendo" e começasse a viver. É como se o efeito da anestesia estivesse passando... (Estudante T)

Escolher a narrativa de história de vida como estratégia de ensino-aprendizagem na formação de futuros profissionais de saúde é uma opção política, no sentido de ser uma resistência com relação a certos modos de transmitir conhecimentos calcados na cisão entre sujeito e contexto sociocultural, arte e vida. É uma proposta que encadeia a produção de saberes com a experiência dos sujeitos envolvidos no processo: o professor, o estudante e os narradores do Naps; além de uma possibilidade de articular inspirações teóricas, afetivas, artísticas e outros processos que se dão em sua realização. Isso porque a transitoriedade entre a verticalidade da história singular e a horizontalidade da cultura é condição para produzir uma história de vida.

Nesse sentido, pode-se dizer que, no que se refere a possíveis dificuldades atreladas à novidade desta estratégia, para muitos estudantes e docentes, estas aparecem mais como estranhamentos iniciais, como um pensamento novo produzido com a escrita. Esse deslocamento da conhecida avaliação por meio de provas, própria de metodologias tradicionais, apresenta-se, portanto, como necessário neste contexto em que o estudante tem um papel ativo em seu processo formativo. A experiência de escrita permite a ele se apropriar do seu percurso de aprendizado, da produção de sua subjetividade e da constituição de seu lugar profissional.

Assim, os três módulos têm se configurado como importante espaço de formação, no qual cada estudante exercita cartografar sua subjetividade, a das pessoas que estão ao seu redor e a dos usuários do Naps. Este trabalho produzido como memorial, inventário ou narrativa de história de vida funciona, assim, como estratégia de ensino-aprendizagem na formação que, no momento da escrita de si e do outro, pode disparar e produzir reflexões sobre o processo de formação cultural e autorreflexões que problematizam sua singularidade e questionam alguns aspectos da cultura contemporânea que corroboram o individualismo e a concepção de que o sujeito se faz sozinho, em detrimento das condições oferecidas por uma sociedade marcada pela desigualdade. O encontro com situações de sofrimento, enquanto modos diversos de adoecer, faz pensar em sua própria trajetória e em seu compromisso profissional. O reencontro com as memórias de brincadeiras da infância, com sua história de vida e com o pensamento desconexo de usuários de saúde mental, desperta este escritor criativo ${ }^{10}$, que havia abandonado seu contato com o devanear, com sua criança, com sua reinvenção da realidade. Poderíamos dizer que, por meio desse envolvimento com a escrita, que não acontece sem implicação, os universitários têm a oportunidade de praticar as técnicas de si: as narrativas escritas de si podem funcionar como práticas da liberdade que, no contexto de um processo formativo, inventam modos de existência que se contrapõem aos discursos normalizadores e às imposições hegemônicas de modos de estar no mundo. 


\section{Colaboradores}

A autora Prof ${ }^{a}$ Dra Jaquelina Imbrizi contribuiu na concepção do texto e participou ativamente junto com os outros três autores - Profa ${ }^{2}{ }^{a}$ Adriana Barin de Azevedo, Prof. Dr. Fernando Kinker e Prof ${ }^{a}$ Dr $^{a}$ Andrea Jurdi - da discussão dos resultados, da revisão e aprovação da versão final do artigo.

\section{Referências}

1. Ministério da Educação (BR). Resolução CNE/CES 6/2002. Diretrizes Curriculares Nacionais. Diário Oficial da União. 4 Mar 2002. Seção 1, p. 12.

2. Ministério da Saúde (BR). Lei no 8.080, de 19 de Setembro de 1990. Dispõe sobre as condições para a promoção, proteção e recuperação da saúde, a organização e o funcionamento dos serviços correspondentes e dá outras providências. Diário Oficial da União. 19 Set 1990.

3. Mitre $S M$, Siqueira-Batista R, Girardi-de-Mendonça JM, Morais-Pinto NM, Meirelles $C A B$, Pinto-Porto $C$, et al. Metodologias ativas de ensino aprendizagem na formação profissional em saúde: debates atuais. Cienc Saude Colet. 2008; 13(2):2133-44.

4. Adorno T. Educação e emancipação. Rio de Janeiro: Paz e Terra; 1965/1995. p. 119-38.

5. Rago M. Introdução - Balizas. A aventura de contar-se: feminismos, escrita de si e invenções de subjetividade. Campinas: Editora da Unicamp; 2013. p. 23-59.

6. Foucault M. A escrita de si. O que é um autor? Lisboa: Passagens; 1992. p. 129-60.

7. Vernant JP. O indivíduo na cidade. In: Veyne P, Ricoeur P, Vernant JP. Indivíduo e Poder. Lisboa: Perspectivas do Homem, Edições 70; 1988, p. 25-44.

8. Rivera T. A Excrita de Hélio Oiticica. Rev Poiésis. 2011; 17:53-64.

9. Freud S. A transitoriedade (1916). In: Souza PC, organizador. Obras Completas. São Paulo: Companhia das Letras; 2010a. v. 12, p. 247-52.

10. Escritores criativos e devaneio (1908). In: Salomão J, organizador. Obras psicológicas completas de Sigmund Freud. Rio de Janeiro: Imago; 1976.

11. Imbrizi JM, Matsubara FK, Silva MLF. A arte de narrar a história de uma vida em Orhan Pamuk: possíveis aproximações com as ideias de Sigmund Freud. Fractal Rev Psicol. 2014; 26(esp):695-714.

12. Imbrizi JM, Matsubara FK, Silva MLF. Na companhia de Orhan Pamuk: literatura e narrativas de história de vida. In: Lages $\mathrm{R}$, organizador. Psicologia social em experimentações: arte, estética e imagem. Florianópolis: Abrapso, Edições do Bosque; 2015. (Coleção Práticas Sociais, Políticas Públicas e Direitos Humanos.)

13. Pamuk O. Istambul: memória e cidade. São Paulo: Companhia das Letras; 2007.

14. Adorno T, Horkheimer M. Indústria cultural: o esclarecimento como mistificação das massas. In: Adorno T, Horkheimer M, organizadores. Dialética do esclarecimento. Rio de Janeiro: Zahar; 1971/1984.

15. Marcuse $H$. As novas formas de controle. In: Marcuse $H$. Ideologia da sociedade industrial. Rio de Janeiro: Zahar; 1964/1967.

16. Lima EMFA, Pastore MDIN, Okuma DG. As atividades no campo da terapia ocupacional: mapeando a produção científica de terapeutas ocupacionais brasileiros de 1990 a 2008. Rev Ter Ocup Univ São Paulo. 2011; 22(1):68-75.

17. Rhoden C. Tarja Branca - a revolução que faltava. São Paulo: Maria Farinha Filmes; 2014. (Documentário). 
18. Fortuna TR. A formação lúdica docente e a universidade: contribuições da ludobiografia e da hermenêutica filosófica [tese]. Porto Alegre (RS): Faculdade de Educação; 2011.

19. Passos E, Kastrup V, Escossia L, organizadores. Pistas do método da cartografia: Intervenção e produção de subjetividade. Porto Alegre: Sulina; 2009.

20. Deleuze G. Conversações. São Paulo: Editora 34; 1992. 
A produção escrita de narrativas tem se apresentado como estratégia de ensinoaprendizagem na formação em saúde do campus Baixada Santista da Universidade Federal de São Paulo. Neste artigo, discutimos como os estudantes se apropriam desta atividade e como os professores estabelecem critérios para avaliar o material que substitui a prova. São apresentadas três experiências: o memorial; a biografia sobre o brincar e a história de vida dos usuários de um Núcleo de Atenção Psicossocial (Naps). O método se baseou na escolha de trechos dos escritos dos estudantes de 2014 e posterior análise à luz de autores que discutem narrativas. Os dados produzidos apontam a importância de considerar o processo criativo na elaboração de um texto; a transitoriedade entre a verticalidade da história singular e a horizontalidade da cultura; e a reflexão acerca da constituição subjetiva no encontro com a diferença.

Palavras-chave: Narrativa de história de vida. Processos de produção de subjetividade. Formação em saúde.

\section{Life narratives as a teaching-learning strategy in health education}

The written production of narratives has been used as a teaching-learning strategy in health education in the Baixada Santista campus of the Federal University of Sao Paulo. In the present study, the authors discuss how students explore this activity and how professors establish criteria to evaluate the material, which replaces conventional tests. Three experiences are presented: memorial, a biography about playing, and life history of users of a psychosocial care center. The method was based on the choice of excerpts from texts written by students of the class of 2014 and a posterior analysis grounded on the ideas of authors who discuss storytelling. The data points to the importance of considering the creative process when drafting a text, the transience between the verticality of a singular history and the horizontality of culture and the reflection on the subjective constitution in the encounter with difference.

Keywords: Life history narrative. Subjectivity production processes. Health education.

\section{Narrativas de vida como estrategia de enseñanza-aprendizaje en la formación en salud}

La producción escrita de narrativas se ha presentado como estrategia de enseñanzaaprendizaje en la formación en salud del campus Baixada Santista de la Universidad Federal de São Paulo. En este artículo discutimos cómo los estudiantes se apropian de esta actividad y cómo los profesores establecen criterios para evaluar el material que sustituye el examen. Se presentarán tres experiencias: el memorial, la biografía sobre el jugar y la historia de vida de los usuarios de un Núcleo de Atención Psicosocial (Naps). El método se basó en la elección de trechos de los escritos de los estudiantes de 2014 y análisis posterior a la luz de autores que discuten narrativas. Los datos producidos señalan la importancia de considerar el proceso creativo en la elaboración de un texto, la transitoriedad entre la verticalidad de la historia singular y la horizontalidad de la cultura y la reflexión sobre la constitución subjetiva en el encuentro con la diferencia.

Palabras clave: Narrativa de historia de vida. Procesos de producción de subjetividad. Formación en salud.

Submetido em 06/04/17. Aprovado em 09/09/17. 